\title{
Hereditary Thyroid Gland Medullary
}

\section{Carcinoma}

National Cancer Institute

\section{Source}

National Cancer Institute. Hereditary Thyroid Gland Medullary Carcinoma. NCI

Thesaurus. Code C46099.

A medullary thyroid gland carcinoma inherited through an autosomal dominant mode. It

is associated with multiple endocrine neoplasia type II (2a) or III (2b). 